\title{
Single and Joint Toxicological Effect of Dispersit SPC 1000 and Bonny Oil on Mudskipper Fish (PeriophthalmusPapilio) from the Brackish Waters of Buguma, Rivers State, Nigeria
}

\section{${ }^{* 1,3}$ KORANTENG-ADDO, EJ; ${ }^{1}$ HORSFALL, M Jnr; ${ }^{3} \mathrm{JOEL}$, OF $;{ }^{2}$ BENTUM, JK}

\author{
${ }^{I}$ Department of Pure and Industrial Chemistry, University of Port Harcourt, Port Harcourt, Nigeria. \\ ${ }^{2}$ Department of Chemistry, University of Cape Coast, Cape Coast, Ghana. \\ ${ }^{3}$ World Bank Africa Center of Excellence in Oilfield Chemicals Research (ACE-CEFOR), University of Port Harcourt, Port Harcourt, \\ Nigeria. \\ *Corresponding Author Email: ekoranteng-addo@ucc.edu.gh, Tel: +233244726176
}

\begin{abstract}
Marine oil spillage accidents greatly impact major risks to the environment in terms of the acute and chronic adverse effects not only to the offshore, but also the coastal ecosystem. This study assessed single and joint toxicological effect of Dispersit SPC 1000 and Bonny Oil on mudskipper fish (Periophthalmus papilio) from the brackish water research station of African Regional Aquaculture Centre, Buguma, Rivers State, Nigeria. The physicochemical parameters observed throughout the study were the $\mathrm{pH}$, alkalinity and salinity were $6.83 \pm 0.1,40$ $\mathrm{mg} / \mathrm{L} \pm 0.2$ and $17,655 \mathrm{mg} / \mathrm{L}$ respectively. The temperature and Dissolved oxygen (D.O.) and specific gravity averaged $26.7^{\circ} \mathrm{C} \pm 0.1,5.70 \mathrm{mg} / \mathrm{L} \pm 0.02$ and $1.008 \pm 0.001$, respectively. Dispersit SPC 1000 was found to be toxic to the mudskipper at various \% (v/v) concentration, above $60 \%(\mathrm{v} / \mathrm{v})$ concentration no fish survived after one hour. The relation between the probit mortality and log concentration showed a strong positive correlation between the dispersant concentration and fish mortality within 3 hours, with $\mathrm{r}^{2}=0.813 \mathrm{p}=0.05$; The lethal dose $\mathrm{Lc}_{50}$ was $73.48 \%$. Within 6 hours, the mortality increased as the dispersant exposure concentration was increased $\left(r^{2}=0.872, p=0.05\right)$. The results of exposure of the mudskippers to the water-oil-dispersant mix (CEWAF) showed lower mortalities. Mortality was observed after 72 hours for dispersant concentration above $54 \% .63 \%$ dispersant concentrations, $20 \%$ mortalities was observed between 72 and 96 hours. Dispersit SPC 1000 alone was highly toxic, and the toxicity of CEWAF was primarily caused by the presence of dispersant. There was no joint increase in toxicity between bonny oil and the chemical dispersant, as the mixing of the dispersant by the oil resulted in diminished toxicity of CEWAF and lower mortality.
\end{abstract}

\section{DOI: https://dx.doi.org/10.4314/jasem.v22i11.18}

Copyright: Copyright ( $\odot 2018$ Koranteng-Addo et al. This is an open access article distributed under the Creative Commons Attribution License (CCL), which permits unrestricted use, distribution, and reproduction in any medium, provided the original work is properly cited.

Dates: Received: 12 October 2018; Revised: 26 November 2018; Accepted 30 November 2018

Keywords: Joint Toxicity, Dispersit SPC1000, Mudskipper Fish

Anthropogenic pollutants and physical disturbances on marine and estuarine plants, animals, ecosystems and habitats have had toxic and adverse biological effects aquatic organisms and human (Alan et al., 2013). Aquatic organic organisms, particularly fishes respond differently to the toxic effects of these pollutants Zhibing et al., 2012). The Mudskippers, a group of goggle-eyed amphibious fish that are uniquely adapted to live on mudflats gobies (You et al., 2014; Gordon et al., 1969) and are entirely different from many other fishes as they can breathe comfortably, in water, as well as in air (Graham, 1997; Adeyemi and Deaton, 2012). They have been found to exhibit tolerance to contaminants and sturdiness to environmental stressors, which give them the capacity to be chronically exposed to toxicants without significant acute effects Guardiola, et al., (2012), while their relatively low trophic status makes them less prone to biomagnifying toxicants (Polgar, et al.,2010 ; Xinxin et al., 2018). These fishes are airbreathing, and are widely distributed throughout the West Africa Coast and the Indo - Pacific region Polgar and Richard (2010). They are closely linked to mangrove and adjacent soft bottom peri-tidal ecosystems. They are benthic burrowers in anoxic sediments Ishimatu and Gonzales (2011), and since tidal mudflats are efficient sediment traps, and sinks for nutrients and other chemical compounds (Abid et al., 2014), they are constantly in contact with several types of pollutants. Mudskippers are remarkably high ammonia-tolerant fish and possess various strategies to ameliorate ammonia toxicity during exposure to environmental ammonia. (You et al., 2018; You et al., 2014; Weihrauch et al., 2009). Although Mudskippers have been found to exhibit tolerance to contaminants and sturdiness to environmental stressors, Dabrussi et al., (2011) they are not able to resist the oil pollution unlike other fish as they spend most of time out of and 
are in direct contact with water polluted with oil (Feng, 2003; Shirani, 2012).The accumulation of toxic substance is of public health concern. The Codex Alimentarius, which is overseen by the World Health Organization (WHO) and Food and Agriculture Organization of the United Nations (FAO), both recognizes and encourages the application of seafood depuration WHO and FAO (2009). The toxic effects of petroleum hydrocarbon on aquatic organism have been determined by various workers (Kadar, et al., 2005; Ansari et al., 2012).Mudskippers have been found to be highly sensitive to very low concentrations of water soluble fraction of petroleum fuel (Shirani et al., 2012; Dutton and Fisher, 2012). The additions of dispersants to the water accumulated fraction enhance the toxicity of oil toward various aquatic organisms as the total petroleum hydrocarbon concentration (TPH) increases (Sheryll et al., 2015; Dang et al., 2012).

However, the toxicological effect of this dispersant (Dispersit SPC 1000) and it's combining crude the Bonny oil has not been investigated for mudskipper fish. Therefore, this study investigated the single and joint toxicological effect of dispersit SPC 1000 and bonny oil on mudskipper fish (periophthalmus papilio) from the brackish waters of Buguma, Rivers State, Nigeria. Mudskippers were used because of their economic significance, and also have been found to exhibit high tolerance to contaminants. The dispersant, Dispersit SPC 1000, was selected for study because oil dispersed with Dispersit SPC 1000 have been found to be toxic to two standard test species USEPA,(2002). The acute toxicity ( $\mathrm{LC}_{50}$ of Dispersit SPC 1000 only to some species have been found to be: Menidia Bahia, 48 hour 16.6 ppm; Menidia Berylilina, 96 hour 3.5 ppm. In oil and Dispersit SPC 1000 (10:1 $\mathrm{V}: \mathrm{V})$ mixture the toxicity, $\mathrm{LC}_{50}$ to the two species Menidia Bahia and Menidia Berylilina were respectively 48 hour $8.2 \mathrm{ppm}$ and 96 hour $7.9 \mathrm{ppm}$ (Heather et al., 2016). Moreover, Dispersit SPC 1000, is composed of highly effective emulsifiers, dispersants and a water-soluble coupling solvent, is very effective in fresh and brackish water, and maintains effectiveness when diluted with water unlike other petroleum based products BP, 2010; $\mathrm{BP}(2011)$.

\section{MATERIALS AND METHODS}

Sampling Site: The sample species were obtained from the brackish water research station of African Regional Aquaculture Centre, Buguma, Rivers State, Nigeria. Buguma is situated at $4.73^{\circ}$ North latitude, $6.86^{\circ}$ East longitude and 378 meters elevation above the sea level. The research was then carried out at Pollution Control and Environmental Management
Limited (POCEMA) Laboratory at Rumuodomanya, Port Harcourt, River State, Nigeria.

Source of Experimental Fish: Two hundred and fifty (250) adult, mudskipper P. Papilio of equal size were collected from the mangrove swamps in Buguma creek at low tide using locally made fishing trap. They were then transferred in six 50 liter plastic tanks to the laboratory for acclimation process.

Acclimation and Feeding of Fish: Various water media of different composition of distilled and saline waters were used to assess the most suitable medium of acclimatization for the test organism. The experimental fish were acclimated in six $150 \mathrm{~L}$ capacity circular plastic tanks containing $150 \mathrm{~L}$ dechlorinated water and mud at the bottom. They were then acclimated for 14 days before the formal toxicological tests were performed. A temperature of $28 \pm 1{ }^{0} \mathrm{C}$ and a $\mathrm{pH}$ ranging from 7.4 to 8.1 was observed during the testing. The fish used in the acute and sub chronic tests were domesticated under the aforementioned conditions for two weeks to acclimate them to the test conditions. The fish were fed with crushed freshly killed crabs each day at regular intervals until $24 \mathrm{~h}$ before the acute and sub-chronic tests were performed. Netted materials with central slits were tied to the tops of the tanks to prevent escape of fish. Water was redrawn once every day for physicochemical analysis.

The study involved the examination of acute toxicity of Dispersit SPC 1000 and dispersant light crude oil mixtures on mud skipper fish. The static renewal toxicity test method was employed. Assessment of crude oil - only and dispersant- oil toxicity was determined using water accommodated fractions (WAF) of Dispersit SPC 1000 and chemicallyenhanced water accommodated fractions (CEWAF) of crude oil (Sikoki and Lelei 2013).

Preparation of Test Stock Solution: Chemically enhanced water accommodated fraction (CEWAF) of crude oil were prepared under laboratory conditions, in closed, low energy mixing systems recently internationally adopted through the "CROSERF" forum (Chemical Response to Oil Spills - Ecological Effects Research Forum).The preparation was done following methods proposed by Sikoki and Lelei (2013); Hemmer et al (2010); Fuller and Rotton et al (1999) and OECD 2014(4) for the preparation of WAF After $24 \mathrm{~h}$ of stirring, 1:10 ratio "high dose" of Dispersit SPC 1000 to crude oil, was added (per standard recommendation for dispersant toxicity for maximum effect, Hemmer et al.(2010). After $1 \mathrm{~h}$ of additional stirring, the stir plate was shut off and the 
CEWAF was allowed to settle for $12 \mathrm{~h}$, after which time the bottom layer was collected in the same way as the WAF. All treatments were made from the same sample of bonny crude oil. Replicates of the test organisms were exposed to different levels of concentrations of CEWAF, every $24 \mathrm{~h}$ during the definitive test water samples and analyzed.

Acute Toxicity Test: Exposure of Fish to Dispersit SPC 1000: 20 Mudskippers each were introduced individually into 6 tanks, of dimension $1.5 \mathrm{~m} \mathrm{x} 1 \mathrm{~m} \mathrm{x}$ $0.5 \mathrm{~m}$ containing various concentrations of Dispersit SPC 1000 of between $0-100 \%$ (v/v). Each treatment(s) replicated twice and the experimental duration lasted for a period of 96 hours. The solution for each concentration was renewed daily, with freshly prepared solution of Dispersit SPC 1000. The tanks were covered with netted materials and supported with heavy objects to prevent the mudskipper from escaping. The mortality was monitored at fixed intervals of 12, 24, 36, 48, 60, 72, 84 and 96 hours. Dead fish were counted at $12 \mathrm{~h}$ intervals and removed from aquaria. A fish was considered dead when it showed no visible movement (e.g. gill movements) and touching its caudal peduncle did not produce any reaction

Exposure of Fish to light crude oil and CEWAF: The threshold concentration was determined by using the protocols adopted by Hemmer et al (2010); OCED 2014(4); OECD (1992) and OPPTS 850.1075, (1996). A preliminary range finding test was done on CEWAF of the dispersant and crude oil to determine the threshold concentrations at which minimum responses were recorded and concentrations levels noted, (where the anticipation level was expected to be $100 \%$ fatality), which was followed by finding a definitive test to determine the $\mathrm{LC}_{50}$. Then test organisms were separately exposed to the following: blackish waterdistilled water mixture $(50 \%)$, bonny oil ( $50 \%)$ and then replicates of different levels of concentrations of CEWAF. Every $24 \mathrm{~h}$ during the definitive test, water samples were drawn and analyzed for the physicochemical parameters
Statistical Analysis: Data analysis of all the results was carried out with IBM SPSS version 22 (IBM, Armonk, NY, USA) and XLSTAT module 2018, from which the Probit Analysis was done to determine the lethal concentrations that killed $50 \%$ of the population. One way ANOVA was computed to determine the differences in the physicochemical parameters.

\section{RESULTS AND DISCUSSION}

Water Quality characteristics: The results of the water Quality characteristics and assessment of the most suitable water medium of acclimatization for the test organism are presented in Tables $1 \& 2$. The $\mathrm{pH}$, alkalinity and salinity were $6.83 \pm 0.1,40 \mathrm{mg} / \mathrm{L} \pm 0.2$ and $17,655 \mathrm{mg} / \mathrm{L}$ respectively. The temperature and Dissolved oxygen (D.O.) and specific gravity averaged $26.7^{\circ} \mathrm{C} \pm 0.1,5.70 \mathrm{mg} / \mathrm{L} \pm 0.02$ and $1.008 \pm$ 0.001 , respectively. One way ANOVA results showed that there were no significant differences between $\mathrm{pH}$, temperature, Total Dissolved Solids (TDS), salinity, Dissolved Oxygen (DO) and alkalinity for all the media used for the toxicity study, however, with Electrical conductivity (EC), and hardness indicated that there were some significant differences. Tables 2 , indicates that the most suitable water medium that showed $80-85 \%$ survival of the mudskipper fish was the diluted brackish water $(50 \%$ blackish waterdistilled water mixture. All mudskippers exposed to bonny oil only and various composition of oil-water mix survived after 96 hours (Table 3). This suggests that the toxicities of the oil and the oil-water mix were not high enough to cause mortality to the fish. The results of mudskipper exposure tanks with dispersant concentration between $0-100 \%(\mathrm{v} / \mathrm{v})$ used for the toxicity studies of the toxicity of the dispersant only is presented in Table 4. The dispersant. Dispersit SPC 1000 was found to be toxic to the mudskipper at various (v/v) concentration No fish survive at $5 \%(\mathrm{v} / \mathrm{v})$ concentration after 6 hours. Also 100\% mortality was observed for $15 \%$ (v/v) concentration Dispersit SPC 1000 after 3 hours. Above $60 \%$ (v/v) concentration NO fish survived after one hour.

Table 1: Water Quality characteristics

\begin{tabular}{llllll}
\hline S/No & Parameters & $\begin{array}{l}\text { Saline } \\
\text { and fresh water }\end{array}$ & $\begin{array}{l}\text { water } \\
\text { Bater } \\
\text { wash }\end{array}$ & $\begin{array}{l}\text { Fresh } \\
\text { water }\end{array}$ & CEWAF \\
\hline 1 & $\mathrm{pH}$ & $6.83 \pm 0.1$, & 7.44 & 4.43 & 6.0 \\
2 & Temperature ${ }^{\circ} \mathrm{C}$ & $26.7 \pm 0.1$ & 27.3 & 26.8 & 29.1 \\
3 & Electrical Conductivity, $\mu$ S/cm EC & 17.40 & 41.6 & 0.23 & 0.07 \\
4 & Total Dissolved Solid, TDS ppm & 8.62 & $25,000.00$ & 110.0 & 40.0 \\
5 & Specific Gravity, S.G & 1.008 & 1.02 & 1.00 & \\
6 & Salinity mg/L & $17,655.00$ & 21,450 & 146.00 & 183.15 \\
7 & Alkalinity mg/L & $40.0 \pm 0.2$ & 340 & 40.00 & 20 \\
8 & Dissolved Oxygen, DO ppm & $5.70 \pm 0.02$ & 2.59 & 5.11 & 6.50 \\
9 & BOD ppm & 4.17 & 0.14 & 0.28 & 5.41 \\
10 & Hardness mg/L & 2,000 & $6,000.00$ & 40.00 & 20 \\
13 & Total Petroleum ppm Hydrocarbon $(\mathrm{TPH})$ & - & - & - & 48.55 \\
\hline
\end{tabular}


Table 2: Mudskipper fish mortality in various water media of acclimatization

\begin{tabular}{cllll}
\hline, & Medium & $\begin{array}{l}\text { Number of test } \\
\text { organisms }\end{array}$ & Mortality & $\begin{array}{l}\text { Percentage } \\
\text { Survival }\end{array}$ \\
\hline \multirow{2}{*}{ 1st } & Mudskipper + Mud + Saline Water & 20 & 16 & 20 \\
& Mudskipper + Mud + Saline Water & 20 & 19 & 5 \\
\multirow{2}{*}{ 2nd } & Mudskipper + Distilled Water & 20 & 12 & 40 \\
& Mudskipper + Distilled Water & 20 & 8 & 60 \\
\multirow{2}{*}{ 4th } & Mudskipper + 40\%Distilled Water + 60\% Saline Water & 20 & 12 & 40 \\
& Mudskipper +40\% Distilled Water +60\% Saline Water & 20 & 14 & 30 \\
& Mudskipper +(50\% Distilled + 50\% Saline) Water & 20 & 3 & 85 \\
& Mudskipper + (50\% Distilled + 50\% Saline) Water & 20 & 4 & 80 \\
\hline
\end{tabular}

Table 3: Mudskipper fish mortality in Bonny oil and various oil-water media of acclimatization

\begin{tabular}{llll}
\hline $\begin{array}{l}\text { Medium (percent crude bonny oil in } \\
\text { prepared water }\end{array}$ & $\begin{array}{l}\text { Number of Test } \\
\text { Organisms }\end{array}$ & $\begin{array}{l}\text { Mortality } \\
\text { Rate }\end{array}$ & $\begin{array}{l}\text { Percentage } \\
\text { Survival }\end{array}$ \\
\hline 0\% Crude Oil + 100\% Prepared Water & 5 & 0 & 100 \\
20\% Crude Oil + 80\% Prepared Water & 5 & 0 & 100 \\
40\% Crude Oil + 60\% Prepared Water & 5 & 0 & 100 \\
60\% Crude Oil + 40\% Prepared Water & 5 & 0 & 100 \\
80\% Crude Oil + 20\% Prepared Water & 5 & 0 & 100 \\
100\% Crude Oil + 0\% Prepared Water & 5 & 0 & 100 \\
\hline
\end{tabular}

Table 4: Result of Acute Toxicity of Dispersit SPC 1000 to mudskipper

\begin{tabular}{lllllll}
\hline Concentration & \multicolumn{6}{l}{ Percentage Mortality } \\
$\mathbf{\%}(\mathbf{v} / \mathbf{v})$ & $\mathbf{1 ~ H r}$ & $\mathbf{2} \mathbf{H r}$ & $\mathbf{3} \mathbf{H r}$ & $\mathbf{4 H r}$ & $\mathbf{5 H r}$ & $\mathbf{6 H r}$ \\
\hline 0 & 0 & 0 & 0 & 0 & 0 & 0 \\
1 & 0 & 0 & 0 & 0 & 0 & 0 \\
5 & 0 & 20 & 40 & 40 & 80 & 100 \\
10 & 0 & 40 & 80 & 100 & 100 & 100 \\
15 & 0 & 40 & 100 & 100 & 100 & 100 \\
20 & 20 & 80 & 100 & 100 & 100 & 100 \\
40 & 60 & 60 & 100 & 100 & 100 & 100 \\
60 & 100 & 80 & 100 & 100 & 100 & 100 \\
\hline
\end{tabular}

The relation between the probit mortality and log concentration (Figure 1) showed within 3 hours, that is a strong positive correlation between the dispersant concentration and fish mortality with $\mathrm{r}^{2}=0.813$ $\mathrm{p}=0.05$; and $\mathrm{y}=3.95 \mathrm{x}-2,202$ (Fig. 1). The lethal dose Lc 50 was $73.48 \%$. Within 1-6 hours, the mortality increased as the dispersant exposure concentration was increased $\left(\mathrm{r}^{2}=0.872, \mathrm{p}=0.05\right)$ and $\mathrm{y}=3.438 \mathrm{x}$ 2.217 as shown in Figure 2. The coefficient of determination $\left(\mathrm{r}^{2} \times 100\right)$, which is an expression of the effect of the varied concentration on mudskipper mortality, was $81.3 \%$ within 3 hours and $67.3 \%$ in 5 hours. Thus the mortalities for an exposed concentration increased with the exposure time. The coefficient determinations suggest that the mudskipper mortality was not solely due to the dispersant. Other factors such as the released PAHs and stress might have contributed to the mortalities as reported by (Arditsoglou and Voutsa, 2012; BP. (2010). The results of exposure of the mudskippers to the wateroil-dispersant mix (CEWAF) showed lower mortalities. Mortality was observed after 72 hours for dispersant concentration above $54 \%$. For both $54 \%$ and $63 \%$ dispersant concentrations, $20 \%$ mortalities were observed for both concentrations between 72 and 96 hours. Toxicity tests have shown that in all cases the dispersants, Corexit 9500A, Dispersit SPC 1000 ${ }^{\mathrm{TM}}$ and JD 2000, alone were less toxic than the CEWAF (Hemmer et al., 2010; OSAT (2011) alone Also increase toxicity have been observed under field conditions, have been attributed to exposure to multiple stressors at any given time, and could result in additive, synergistic, or antagonistic effects. Corexit 9500 mixed with Number 2 fuel oil at a 1:10 ratio has been found to be ten times more toxic than Corexit 9500 alone Denison, (2010).

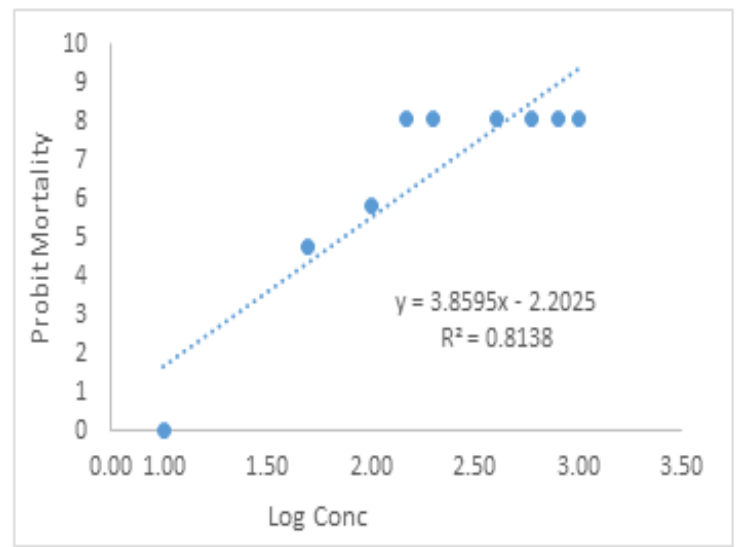

Fig 1: Probit Mortality plots for Acute Toxicity of Dispersant only to Mudskipper within $3 \mathrm{hr}$. $\mathrm{LC}_{50}=73.48 \%$. 


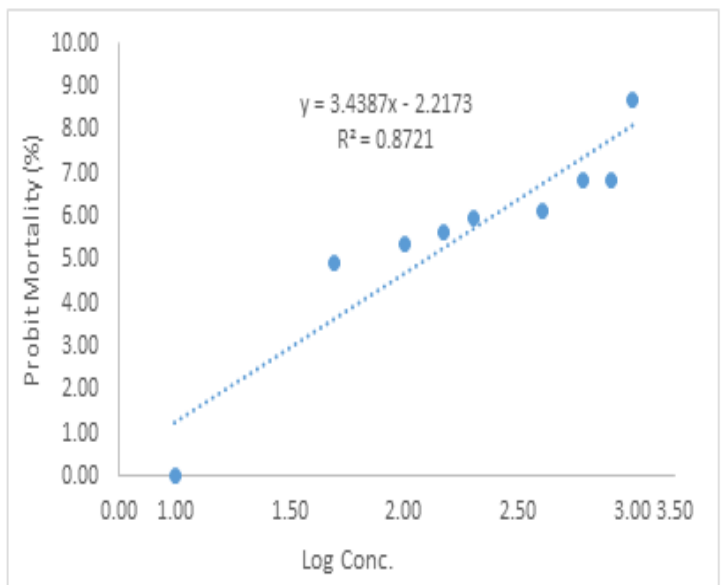

Fig 2: Probit Mortality plots for Acute Toxicity of Dispersant only to Mudskipper within $1-6 \mathrm{hr} \mathrm{LC}_{50}=125.56 \%$

However, the results of this study showed that joint toxicity of CEWAF of bonny oil and the dispersant were less than the dispersant alone. The relatively higher toxicity of Dispersit SPC $1000^{\mathrm{TM}}$ alone compared to the CEWAF prepared from bonny oil dispersed with Dispersit SPC $1000^{\mathrm{TM}}$ could be due to dilution and mixing by the oil, resulting in rapidly diminished exposure concentrations to the mudskippers. This is similar to what have been observed for .dynamic environments. The lower toxicity observed for the CEWAF is not strange, as others have found that the dispersants don't increase the toxicity of the oil, they increase the amount of oil mixed into water by 100 -fold compared to undispersed oil floating on the water Adams et al., 2013; Hodson et al., (2015). Data released by the EPA from its own testing on Corexit 9500 (and seven other dispersants), and concluded that the acute toxicity of the dispersantoil mixture is about the same as the oil by itself Denison, (2010).

The coefficient of determination of the effect of varied dispersant concentration on mudskippers mortality was $76.3 \%$. This also suggests a decreased in toxicity of the dispersant in the oil-dispersant mix, CEWAF. Thus the chemical dispersion of the bonny oil did not increase the risk of toxicity of the CEWAF to mudskipper fish relative to the dispersant only. Mortalities have occurred due to exposure of the fish to the CEWAF, which were partly ascribed to the toxic effect of components of the oil, petroleum hydrocarbons, released into the water-oil-dispersant mix (Santander-Avancen et al., (2016). Even though the addition of dispersant to oil increased the amount of total petroleum hydrocarbons (TPH) and toxic PAHs released into the water-oil- dispersant mix (CEWAF), in this study the toxicity of CEWAF was primarily due to the presence of dispersant since the mudskippers survived in the bonny oil only. In summary, No mortality was observed for the oil only. The mortality caused by the dispersant, Dispersit SPC 1000 , only to mudskippers was higher than that of CEWAF. Thus the oil did not increase the toxicity of the dispersant in the CEWAF. There was no joint increase in toxicity between bonny oil and the chemical dispersant, as the mixing of the dispersant by the oil resulted in diminished toxicity of CEWAF and lower mortality.

Acknowledgements: Support for this work were provided by World Bank ACE-CEFOR of University of Port Harcourt, Nigeria (UNIPORT), and University of Cape Coast, Cape Coast, Ghana. The authors would like to thank all the research, technical staff from Laboratory of Pollution Control and Environmental Management Limited (POCEMA), at Rumuodomanya, Port Harcourt, River State, Nigeria.

\section{REFERENCES}

Abid, A; Ansari, ST; Shalini, S; Hasibur, R (2014) Mudskipper: A biological indicator for environmental monitoring and assessment of coastal waters. J. Entomol. Zoo. Stud. 2 (6): 22-33

Adams, MJ; Miller, DAW; Muths, E; Corn, PS; Grant, EHC; (2013) Trends in Amphibian Occupancy in the United States. PLoS ONE 8(5): - 64347. doi:10.1371/journal.pone.0064347.

Adeyemi, JA; Deaton, LE (2012) The Effect of Cadmium Exposure on Digestive Enzymes in the Eastern Oyster Crassostrea virginica. J. Shellfish Res. 31, 631-634.

Alan, JM; Donald, JR; Philip, SO; Thomas, G; Mary, AR; Courtney, A and Rutherford, N (2013) Effects of Pollution on Marine Organisms Water Environ. Res. 85, 10-17.

Ansari, ZA; Desilva, CBS (2012) Total Petroleum Hydrocarbon in the Tissues of Some Commercially Important Fishes of the Bay of Bengal. Mar. Poll. Bull.64, 2564-2568.

Arditsoglou, A; Voutsa, D (2012) Occurrence and Partitioning of Endocrine-Disrupting Compounds in the Marine Environment of Thermaikos Gulf, Northern Aegean Sea, Greece. Mar. Poll. Bull. $64,2443-2452$.

Bejarano, MD; Marta, GLT; Diego, GJ; Miguel, MAI; Sordo-Ward and Solana-Gutiérrez. J (2012). 
Responses of riparian guilds to flow alterations in a Mediterranean stream. J. Veg. Sci. 23, 443-458.

BP (2010). Dispersant Studies of the Deepwater Horizon Oil Spill Response Interim Report on Surface Application Evaluations Conducted May 17-27, 2010; p 16.

BP (2010). Dispersant Studies of the Deepwater Horizon Oil Spill Response Volume 3; p 32.

CROSERF (Chemical Response to Oil Spills Ecological Effects Research Forum) (1996) Dispersant and Dispersed Oil Laboratory Toxicity Studies Research Plan.

Don Aurand (Ed.) Ecosystem Management \& Associates.

Dabruzzi, TF; Wygoda, ML; Wright, JE; Eme, J; Bennett, WA (2011). Direct evidence of cutaneous resistance to evaporative water loss in amphibious mudskipper (family Gobiidae) and rockskipper (family Blenniidae) fishes from Pulau Hoga, Southeast Sulawesi, Indonesia. J Exper. Marine Bio Ecol. 406:125-129.

Dang, F; Rainbow, PS; Wang, WX (2012) Dietary Toxicity of Field-Contaminated Invertebrates to Marine Fish: Effects of Metal Doses and Subcellular Metal Distribution. Aquatic Toxicology, 120, 1-10.

Dang, F; Wang, WX (2012) Why Mercury Concentration Increases With Fish Size? Biokinetic Explanation. Environ. Pollut. 163, 192-198.

Denison, R (2010) EPA data show dispersants plus oil are more toxic than either alone. /Bio / Published: June 14, 2010.13.

Denison, R (2010). New EPA data: Dispersant likely not to increase acute lethality of oil in BP oil disaster/ $\underline{\text { Bio }}$ / Published: August 2, 2010

Dutton, J; Fisher, NS (2012) Bioavailability of Sediment- Bound and Algal Metals to Killifish Fundulus heteroclitus. Aquatic Biol. 16, 85-96.

Feng, ZP; Doering, CJ; Winkfein, RJ; Beedle, AM; Spafford, JD; Zamponi. GW (2003). Determinants of inhibition of transiently expressed voltage-gated calcium channels by conotoxins GVIA and MVIIA. JBC Papers in
Press. Published on March 24, 2003 as Manuscript M300581200.

Fuller, C; Bonner, J; Page, C; Ernest, A; McDonald, T; and McDonald. S (2004). Comparative toxicity of Oil, Dispersant, and Oil plus Dispersant to several marine species. Environ. Toxicol. And Chem.; 23 (12). 2941-2949.

Gordon, MS; Boëtius, I; Evans, DH; McCarthy, R; Oglesby. LC (1969). Aspects of the physiology of terrestrial life in amphibious fishes. I. The mudskipper, Periophthalmus sobrinus. J. Exp. Biol. (50), 141-149.

Graham, JB (1997). Air-breathing fishes. Evolution, diversity and adaptation. Academic Press, San Diego.

Guardiola, FA; Cuesta, A; Meseguer, J; Esteban, MA (2012) Risks of Using Antifouling Biocides in Aquaculture. Inter. J. Mol. Sci. 13, 1541-1560.

Heather, PF; Carys, L; Mitchelmore, JMM; and Lipton, J (2016) Characterization of Oil and Water Accommodated Fractions used to conduct Aquatic Toxicity Testing in support of the Deep Water Horizon Oil Spill Natural Resource Damage Assessment. Environ. Toxicol. Chem. 99 (9). 1-10.

Hemmer, MJ; Barron, MG; Greene, RM (2010). Comparative Toxicity of Louisiana Sweet Crude Oil (LSC) and Chemically Dispersed LSC to Two Gulf of Mexico Aquatic Test Species; U.S. Environmental Protection Agency Office of Research and Development: 2010; p 13.

Ishimatsu, A; Gonzales, TT (2011) Mudskippers: Front runners in the modern invasion of land. In The Biology of Gobies; Patzner. RA; Van Tassell. JL; Kova`ci'c. M; Kapoor. BG. Eds.; Science Publishers: Enfield, NH, USA, 2011; pp. 609638.

Jensen, LK; Honkanen, JO; Jaeger, I; .Carroll, J. (2012) Bioaccumulation of phenanthrene and benzo a pyrene in Calanus finmarchicus. Ecotoxicol. Environ. Safety. 78, 225-231.

Kadar, E; Costa, V; Santos, RS (2005). Distribution of micro-essential $(\mathrm{Fe}, \mathrm{Cu}, \mathrm{Zn})$ and toxic $(\mathrm{Hg})$ metals in tissues of two nutritionally distinct hydrothermal shrimps. Sci. Tot. Environ; 358:143-150. 
Kruitwagen, GHT; Pratap, HB; Wendelaar, BSE. (2006). Changes in morphology and growth of the mudskipper (Periophthalmus argentilneatus) associated with coastal pollution. Marine Biology. 149: $201-211$

Lelei, KE and Sikoki, FD (2014). Uptake and Depuration of PAHs by Oreochromis niloticus. Exposed to the Dispersed Phase of Bonny Light Crude Oil. Inter. J. Geol. Earth. Amp. Environ. Sci. 4 (2): 182 -190.

Lyons, K; Carlisle, A; Preti, A; Mull, C; Blasius, M; O'Sullivan, J; Winkler, C; Lowe, CG (2013) Effects of trophic ecology and habitat use on maternal transfer of contaminants in four species of young of the year lamniform sharks. Mar. Environ. Res.90: 27-38

(OECD) Organization of Economic Cooperation and Development. (2014) Guidelines for Testing of Chemicals, Guideline 203: Fish Acute Toxicity Test. OECD 2014 (4).

Onduka,T; Kakuno, A; Kono, K; Ito, K; Mochida, K; Fuji, K (2012) Toxicity of Chlorothalonil to Marine Organisms. Fisheries Science, 78, 13011308 .

(OPPTS) Office of Prevention, Pesticides and Toxic Substances. (1996). Ecological Effects Test Guidelines: Fish Acute Toxicity Test, Freshwater and Marine. OPPTS 850.1075.

(OSAT) Operational Science Advisory Team. (2011). Unified Area Command. Summary Report for Sub-Sea and Sub-Surface Oil and Dispersant Detection: Toxicity Addendum; July 8, 2011; p 35.

Polgar, G; Sacchetti, A; Galli, P (2010) Differentiation and adaptive radiation of amphibious gobies (Gobiidae: Oxudercinae) in semi-terrestrial habitats. J. Fish Bio.; 77:1645-1664

Qiong, S; Xinxin, Y; Min, S; Jia, L; Chao, B; Jieming, C; Yunhai, Y and Hui, Yu (2018,) Mudskippers and Their Genetic Adaptations to an Amphibious Lifestyle. Animals 8, 24

Sary, AA; Mohammadi, M. (2012) Lead Bioaccumulation and Toxicity in Tissues of Economically Fish Species from River and Marine Water. Bull. Environ. Contam. Toxicol. $89,82-85$.
Sheryll, S; Santander-Avance; Resurreccion, BS; Hilario, S; Taberna, Jr.; Gilma, TT; Koyama, J (2016). Acute Toxicity of Water-Accommodated Fraction and Chemically Enhanced WAF of Bunker C Oil and Dispersant to a MicroalgaTetraselmis tetrathele. Bull Environ Contam Toxicol 96:31-35

Shirani, M; Mirvaghefi, A; Farahmand, H; Abdollahi, M (2012). Biomarker responses in mudskipper (Periophthalmus waltoni) from the coastal areas of the Persian Gulf with oil pollution. Environ Toxicol Pharmacol; 34(3):705- 13.

USEPA. (2002)Methods for Measuring the Acute Toxicity of Effluent and Receiving Waters to Freshwater and Marine Organisms. 5th Edition. EPA-821-R-02-012. U.S. Environmental Protection Agency, Washington, D.C.; 2002.

Weihrauch, D; Wilkie, MP; Walsh, PJ (2009) Ammonia and urea transporters in gills of fish and aquatic crustaceans. J. Exp. Biol., 212, 17161730. [CrossRef] [PubMed]

39. WHO and FAO. (2009). Code of Practice for fish and fishery products (first edition) Rome ISBN 978-92-5-105914-2

Wong, HL; Giesy, JP; and Lam, PKS (2006) Organochlorine insecticides in mudflats of Hong Kong, China. Archives Environ. Contam. Toxicol. 50: $153-165$.

You, X; Chen, J; Bian, C; Yi, Y; Ruan, Z; Li, J; Zhang, X; Yu, H; Xu, J; Shi, Q (2018). Transcriptomic evidence of adaptive tolerance to high environmental ammonia in mudskippers. Genomics in Press.

You, X; Bian, C; Zan, Q; Xu, X; Liu, X; Chen, J; Wang, J; Qiu. Y; Li, W; Zhang, X (2014). Mudskipper genomes provide insights into the terrestrial adaptation of amphibious fishes. Nat. Commun. (5): 5594.

Zhibing. J; Yijun. H; Quanzhen. C; Jiangning. Z; Xiaoqun. X (2012). Acute toxicity of crude oil water accommodated fraction on marine copepods: The relative importance of acclimatization temperature and body size. Mar. Environ. Res.462: 126 - 132. 